\title{
The Value of Narrative Art in Folklore
}

Anarbai Sagiuly Buldybai

Samalbai Daribayevich Daribaev

Aknur Abduzhaparovna Ospanova

Gulmariya Turysbekovna Ospanova

Al-Farabi Kazakh National University, Kazakhstan, 050040, Almaty, Al-Farabi avenue, 71

Kuanyshbek Esenbekovich Yusupov

Ahmet Yesevi International Kazakh-Turkish University, Kazakhstan, 161200, SKR, Turkestan, B.Sattarkhanov avenue

\author{
Doi:10.5901/mjss.2015.v6n4s1p481
}

\section{Abstract}

The study of folklore contributes to deeper understanding of not only our past, but contemporaneity as well, because they are closely interconnected with each other. The main purpose of this paper is to study art and creative practice of Kazakh narrators, the peculiarities of their repertoire as an integral system, to characterize the narrator schools of Kazakhstan, and also to reveal the correlation of tradition and improvisation in the art of narration. The paper determines the role of epic narrators in social and cultural folk life, as the direct creators and bearers of epic tradition; their creative types are revealed. The art of narration is described based on local peculiarities, style directions, originality of repertoire and other criteria; it is distinctively characterized by its inhering properties. The narrators develop the epic heritage, using the zhels to create the artistic images. These zhels, created on the basis of improvisation, were subsequently turned into stable, unchangeable components of the literary piece; they were supplemented, became the independent pieces and were performed by the narrators directly before large epic pieces. The zhels became the poetic device of Kazakh art of narration, proved in this article.

Keywords: folklore, tradition, the art of narration, epos, syncretism, zhyrau, legend, improvisation, culture.

\section{Introduction}

\subsection{Introduction to the problem}

Uzans, baksy, zhyrau, zhyrshy, kissashy, termeshy are the creators, bearers and performers of the richest folklore heritage of the Kazakh nation - epic pieces. It is obvious, that nobody will deny the huge role of narrators in preservation, formation and communication of global epic pieces from generation to generation. They concentrate centuries-long history and culture of the nation. The study of origin of the abovementioned folklore types, deeper analysis of their functions in oral tradition, revelation of inner regularities of their evolution shall contribute to the solution of different problems of Kazakh epos. A. Formozov, who is involved in the study of ancient representatives of folklore types, underlines: "Not knowing the sources of each phenomenon, it is impossible to know its inner structure. It means that, to understand the role of any art in the social life, we are to investigate thoroughly its manifestation in the ancient world" (Formozov, 1969). These ideas are especially valuable for Kazakh folkloristics. We still do not have the uniform terms for the types of epic narrators and their functions. T. Sydykov fairly mentions, that the problem about closeness and difference of new types of the akyn - zhyrau, zhyrshy, singers (enshy) - has not been studied yet. As if the book "Akyns" by E. Ismailova has finally cleared up the question about the creativity of akyns and zhyrshy, different in character. At the present time, nobody can make a point, proving the exhaustiveness of this traditional problem. M. Zholdasbekov, in this regard, says that, recently, the press pages present different opinions about the akyns, zhyrshy, zhyrau, olenshy (singers) and termeshy (Zholdasbekov, 2000). Subsequently, there is a necessity to classify clearly these notions.

\subsection{The reasons of terminological confusion}

One of the main reasons of terminological confusion and ambiguity of opinions about the functions of folklore types lies in the fact, that one folklore type frequently concentrates the properties, simultaneously typical of different epos creators and 
bearers. The investigators would like to see one definite feature in each type. Thus, akyn-zhyrau presents an independent creative personality, but it can also be considered as one of the types of epic narrators-singers of songs, tolgau and terme. R. Berdibaev accurately notices one of the features, peculiar of the folklore types. He writes, that the worth mentioning problem is the following one: zhyrshy, in their earlier period, were multi-talented representatives of art. Their second distinctive feature is a syncretism. The narrator shall be able to create songs (to be the akyn or zhyrau), to act (zhyrshy), to possess musical art (kyuishy), to have the pleasant voice (to be the singer), to be able to get across the song to the listeners by means of mimics (to possess the artist's talent), to compose, to create motives (to be the composer), to declaim expressively the prosaic inserts in the poetic texts or the text itself, which is narrated directly before the epic song (to possess the declamatory skills), and also to know well the history of development and peculiarities of the genre. Not possessing all qualities, it is impossible to preserve the huge number, even the enumerable number of epic pieces in centuries, in oral form and in memory (Berdibaev, 1999).

The second reason, especially in the last times, of varied opinions about the types of zhyrshy, zhyrau and termeshy, lies in the fact that at the present moment there appeared the art representatives, whose functions do not conform to that role, played by them in the past. For instance, many termeshy are called zhyrau at present, although they cannot be called not only the representatives of individual poetry, but even the zhyrshy-singers. Here is another example. At present, those singers, who sing songs under definite melody, i.e. songsters, are called zhyrau. If the second factor is not taken into consideration, then, it becomes wrong in relation to the previously enumerated representatives of the art of narration. The termeshy of Syr Darya name themselves zhyrau, as they adopted their traditional epic chants of Zhienbay, Bazar, Nurtagan and Nartay quite well, as well as the tolgau and terme of Syr Darya zhyrau, poets. Some of them narrate even one-two parts of the dastan "Korogly". That is why they ask a quite relevant question - "Who will not name us zhyrau?" If to speak about real, true zhyrau (in the latter word meaning), then it is necessary to take into consideration, that they not only performed the enumerable epic pieces, but also were the improvisators, who could include new plots to the piece. They created tolgau and terme, frequently participated in aytys. Except the earlier representatives of this art, it is enough to name such famous narrators, as R. Mazkozhaev, K. Rustembekov, Zh. Aralbaev, A. Taskynbaev, K. Imangaliev, N. Ramankulov, B. Zhusupov, A. Almatov and others.

It is also necessary to say, that those, who narrate five-six short tolgau and terme, thus naming themselves zhyrau, bring confusion to definition of narrator types, causing fair discontent in public environment. It can be met in arkinsk and zhetysuisk traditions of narration. Narrating tolgau, terme and epic songs under the song melody, they name themselves zhyrshy and termeshy, but the nation does not perceive them so.

\section{Procedure}

\subsection{The main investigation principles of the art of narration}

Teaching the art of narration is a complex process. The foundational role is played by the narrator genius, epic tradition, vivid epic environment etc. If the epic environment and tradition are the objective factors in formation of the narrator, than the talent, memory, vocal skills of the narrator (singing, playing the musical instrument) are the subjective factors. Comparative-typological study of the narration art of the Kazakh and other Turkic-speaking nations will provide an opportunity to reveal general and individual traits in it. The Kazakh narration uses the musical instruments - kobyz, dombra, and later - harmonica.

A method of direct observations involves the study of life, creativity and acting skills of folk narrators, both living at present and those, who lived before; thorough study of samples of epic pieces, written in different time, systematic observation over the processes, taking place in vivid epic tradition; historical-comparative and typological methods. One of the interesting poetic devices is the "necklace of songs" (zhel), which prepared the audience to perceive the large epic piece.

The investigation process deals with the problems, what folklore types in the history of Kazakh nation were directly connected with creation of epic songs, their narration and development, what songs promoted their communication from generation to generation, what changes happened with the functions of these folklore types in the course of historical development of the society.

Uzans can be called the first creators and bearers of epic pieces. The first data about uzans are met in the works of A. Margulan; he writes, that in the historical epoch of Korkyt on Syr Darya, inhabited by Oguz-Kipchak tribes, there lived a genius starets, the nation descent, adviser, a perfect akyn (uzan), who could forereach and predict the future. A. Konyratbaev provides the exact data about these folklore types. "In the songs of old man Korkyt, the Oguz-Kipchak tribes name the epos narrators as "uzans". It is approximately IX-X centuries. The first uzan of Oguz was Korkyt. at that time, 
the song was sang only with the accompaniment of kobyz, in the musical time of kyui" (Konyratbaev, 1987). Alongside with it, his own compositions testify about the indirect creative connection of Korkyt's pieces with the epic songs (KorkytAta, 1986). Uzans not only created the songs and sang them. In the following folklore types, they acquired such features, as the ability to predict the future, to give reasonable pieces of advice, to give guidance to people. Unfortunately, there are no any data, how long the uzans existed, who represented the uzans, apart from Korkyt.

\subsection{The typology of creators of the Kazakh folklore}

The data about "uzan" notion origin can be found in the papers of Russian scientists-Orientalists. Thus, A.K. Borovkov writes: "This word is a Turkic name for a category of people, Turkomen, playing the tanbur, singing songs and narrating oguzname", specifying, that "uzan" names a class of people or tribe, who, playing the guitar (tashbur - A.B.), sing songs and read the predictions" (Borovkov, 1998). V.V. Bartold speaks about the connection of the term "uzan" with epic songs of Oguz tribes, basing himself on the data of the vocabulary of the XVII century "Shuuryga": "The quips and epic folk tales of the nations of Oguz origin in antiquity were equally called oguzname, and the one, who narrated these folk tales, was named uzan" (Bartold, 1968). Afterwards, the term "uzan", alongside with the culture of tribes, which formed the Kazakh nation, passed into the Kazakh oral-poetry writing. The word "uzan" in this meaning is still used in Azerbaydzhan folklore, and, together with the term "ashyg", means the narrators of large epic pieces. The Oguz zhyrau, who narrated the large epic pieces of Karakalpak nation, E. Zhubanov connects with the uzans-zhyrau (Zhubanov, 1978).

The second folklore type, which the investigators connect with the singing of epic songs, is the baksy. There are different viewpoints about the origin of this word. E. Tursynov wrote about it in due course. In the Kazakh language, the word "baksy" is used in two meanings: the first is connected with the art of oratory, narration (it is the akyn, the musician), the second denotes clairsentient, infirmarian, genius, shaman (Tursynov, 2003). Ch. Valikhanov in due course wrote about the connection of Korkyt (named as uzan in due course) with baksy art: "... all this is accompanied by kobyz, the instrument, belonging to aulie Korkyt, and singing, which is named saryn (Valikhanov, 1984). B. Kenzhebaev underlines the many-sidedness of baksy gift. He writes that they and zhyrshy, kyuishy are both infirmarians and clairsentients. Later, the Kazakh nation preserved the types of baksy only as infirmarians and clairsentients, and the Uzbeks, Turkmen and Kara-Kalpaks connect the baksy only with the art of oratory. It is impossible to define precisely, how long they were the epic narrators. If to base on the material of $A$. Konyratbaev, then the baksy-narrators of the Turkic-Mongolian tribes were connected with the art of oratory in the X-XV centuries. Uzans and baksy, complementing each other, developed the art of oratory side by side for a long time. The papers of $A$. Konyratbaev also deal with the more precise data about the functions of baksy, which they fulfilled in the subsequent epoch: "In the XIII-XV centuries, zhyrau "bud off" the baksy. If the baksy's predestination was the cult songs, then zhyrau altogether referred to the civil poetry" (Konyratbaev, 1987). There are no materials indeed, that the baksy were the narrators after the XV century. Besides Korkyt, no one name of baksy-narrator came to us. However, in public environment, there are numerous baksy-infirmarians, forecasters, clairsentients, baksy-kobyzshy, baksy in the religious meaning of the word. K. Aiymbetov provides one curious fact, how the narrating features apeared in the Kara-Kalpak baksy: "Baksy-narratos appeared among the Kara-Kalpak later. Their repertoir was wider, that the one of the zhyrau" (Aiymbetov, 1988). The investigator refers the appearance of narrating features to later epoch. However, from our point of view, the baksy did not acquire these features later, but preserved from ancient times and were subject to significant changes due to historical-economic development of the society. The Kara-Kalpak nation named the narrators of heroic songs as zhyrau, and the narrators of lyrical-epic pieces as baksy.

A special attention shall be paid to the fact, that the baksy thoroughly use the magic and artistic strength of the word. It was described by A.N. Veselovsky: "At earlier stages of human society development, national poetry is closely connected with the magic image, which provided the generic group with the prosperity in war, hunting or collective labor processes. Hence, there is a belief to magical power of song and combination of professions of singer and magicianshaman, typical of the primitive society" (Veselovsky, 2009).

Different Turkic-language nations use the term "baksy" in different meanings. For instance, if Nogais use the word "baksy" in the meaning of the musician, maestro of art, then the Turkmen use the word "bakhshy" to name the professional singer. They underline, that musical talent descends from father to son. Of course, baksy-narrators go to the folk school on purpose to learn this type of art. The Turkmen also use the word "bakhshy" to name the singers and musicians, who learned the ready-made pieces, and the narrators-improvisers are named "shaiir".

\subsection{The characteristics of types of epic narrators}

One more type of epic narrators is zhyrau. L.Z. Budagov, E. Ismailov, N. Smirnova and others connect the origin of this 
word with the words "zhyr", "zhyrlamak". In the vocabulary of V.V. Radlov, such words, as "yr", "yrlyzhy", "yrla", "zhyrau", "zhyraushy" are interpreted as narrators. A. Konyratbaev underlines, that zhyrau devoted themselves to the art of writing, starting from the XV century. However, the investigator does not deny their role in oral-poetic writing.

The first responses of this viewpoint can be found in Turkic dictionary of Makhmud Kashgary "Divany Lugat-At Turk" (XI century). He says, that the Turcomen usually name "yragy" those, who compose songs themselves. When studying ancient documents and historical materials, it is possible to see clearly, that zhyrau, as well as baksy, fulfilled different functions. They created the pieces, were the advisers, heads of troops, narrators. If baksy, in the epoch of their bloom, had the dominating qualities of infirmarians and clairsentients, then later, baksy were more connected with the art of oratory (composition of pieces and their narration). They were mainly the improvisers, advisers and wisemen. It shall be noted that in the art of oratory, they fulfilled two functions. Thanks to the improvisational abilities, they created tolgau, expressing the public viewpoint, the social opinion. Besides, they composed the heroic songs in honor of famous people of their times (later, the epic songs were created based on these pieces). Zhyrau also narrated epic pieces. However, it would be fault to assume, that they fulfilled these two functions simultaneously. At the initial stage, great attention was paid to the individual poetry. A. Margulan underlines, that zhyrau, by nature, are not the akyns, they are the wisemen, advisers, tolgau narrators. They are the genius, thinkers, who encourage and support people in difficult times. They are both teachers and tutors. Zhyrau is the genearch, aksakal, the exponents of nation's hopes and expectations. They improvise tolgau, where they call people for friendship, unity, call to stand up the enemy (Margulan, 1985).

\section{Results}

It is not deniable that the traditional folklore samples at one time were created by authentic authors, it is also obvious, that, later, this authorship was not preserved, and the pieces underwent the editing of many narrators. In this connection, they are called folklore. The medieval akyns and zhyrau created their pieces in oral form. They came down to us in oral form as well.

It is possible to read M. Auezov about the role of zhyrau and genre peculiarities of their peices. He writes, that zhyrau, as distinct from akyns and zhyrshy, have their own specific genres. The zhyrau's tasks and responsibilities do not involve the antheming of everything. Per field of their view is the criticism of their times, anticipation of the century, epoch, and the narration about the historical events and their evaluation. Foremost, they are both zhyrau and bii. Indeed, the investigators of creativity of representatives of individual poetry underline, that, initially, zhyrau wrote songs and tolgau themselves. Ch. Valikhanov mentions, that in the epoch after Korkyt, Asankaygy Sabituly was the founding father of zhyrau, named in due time as uzans, baksy and zhyrau (XV century) (Valikhanov, 1984).

Zhyrau, together with the art of oratory, managed to preserve the features, coming to them from baksy - an ability to give wise pieces of advice and to predict the future: they assimilated new functions - to be the heads of troops, genearches, biys. Although zhyrau, who paid much attention to song composing, pushed to the sidelines the formation of epic world, coming from ancient times, as well as the narration of epic pieces and their popularization, but they did not forget it at all. M. Magauin, studying the peculiarities of individual poetry of zhyrau, said about it well: "Alongside with it, he (Kaztugan) is an epic poet. In some pieces of nogaylinsk period, the influence of Kaztugan's poetry is felt. From this point of view, Kaztugan is one of the first creators of Kazakh epos.Later he underlines: "We do not know, how far the eloquent patriarch (Bukhar) was the creator of epos. Judging by some pieces (for instance, "Fighting with Galdan"), zhyrau had a direct relation to creation of epic songs about batyrs of the XVII century and about Ablay" (Magauin, 1971). After the XVII century, the features of individual creativity (composition) began to fade in zhyrau. Instead of this, another feature strengthened - epic narration. The reason, seen by the investigator, lies in the fact, that "zhyrau were the representatives of ancient patriarchal society. That is why, when the generic Kazakh society began to lose its initial peculiarities, zhyrau began to come off the arena". However, the author brings to nought the fact, that zhyrau were further preserved as epic narrators, and it is impossible to name the zhyrau as the creators of epic songs and the narrators that after Bukhara-zhyrau. One-sidedness of the investigator's approach to the essence of the art of narration is quite obvious. Indeed, in this period and after, the word "zhyrau" was used to denote the epic narrators.

The traditions of epic narration, which were formed in the earlier period thanks to uzans and baksy, reached their bloom, as such prominent creative personalities, as zhyrau, became integrated to the art of writing. The evolution of this process was revealed by N.S. Smirnova: "Later, in the XIX century, zhyrau turns from prophetic wise singer into the narrator" (Smirnova, 1979). They inherited only the art of oratory from the previous zhyrau tradition and left the other features (a capacity for clairvoyance, to be the head of troop, the adviser-wiseman - each separately).

Starting from the XVII cantury, zhyrau entirely turned to epic songs singing. That is why, the epic traditions, directly connected with historical events, began to develop from these times. It is underlined by A. Margulan: "The formation of 
professional singers is closely connected with the origin of epic poetry" (Margulan, 1985).

The term "zhyrau" is also met in Uzbek and Kara-Kalpak folklore, but these nations preserved it only in the meaning "the epic narrator". The investigators of culture of these nations do not name any representative of individual poetry. Kara-Kalpak folklorist K. Aimbetov notices, that "zhyrau, taking kobyz, is the protector of nation's heritage, he sang historical songs in public environment, expressing the most cherished believes of his time". I. Sagitov writes about epic motives of Kara-Kalpak zhyrau in the following way: "I name the narrator of heroic stories "zhyrau"...One of the peculiarities of zhyrau narration is singing in guttural voice" (Sagitov, 1962).

It is necessary to mention that the musical instrument - kobyz, accepted by the Kazakh zhyrau and used after baksy only by akyns, was widely used by the Kara-Kalpak zhyrau. The traditions of epic narration, developed by further generations, at one time included to Oguz tribes, were enriched not only by the Kazakh zhyrau, but also by the KaraKalpak ones. It is also necessary to say, that these epic traditions were preserved in Turkmen and Mountain-Altai nations.

Zhyrshy are another folklore representatives of the narrative art. The term "zhyrshy" is directly connected with the terms "zhyr" and "zhyrau". Thus, the paper of Abulgazy "The Chronicle of Turkomen" (Shadzharat-Al-At-Turk) mentions the zhyrshy Ulug, who informed Genghis-khan of his son Zhoshy death. The paper of K. Khalitov "Tauarikh Khamsa" provides the data, that one group of akyns is called zhyrshy. They are equal to the akyns. In these two investigations, the word "zhyrshy" is used not in the meaning of "narrator", "song singer", but in the meaning "akyn", who creates the poetic pieces. Although the term "zhyrshy" was initially used in this meaning, but another meaning was widely spread in public environment. Zhyrshy is a person, who learned the epic songs and sang them under the definite melody, under the accompaniment of the musical instrument. More precise definition of this term can be found in A. Margulan: "The most numerous group of Kazakh folk singers was constituted by zhirchi (zhyrshy) - the narrators. Zhirchi, the songstes literally, create a little themselves. They sing borrowed songs and plots" (Margulan, 1985).

Zhyrshy, who precisely fulfilled their initial functions, at that times were the improvisers of tolgau, terme, dastans, participated in aitys, promulgating their art in public environment. Alongside with the narrators, zhyrau, who beautified the epic songs with their improvisation, zhyrshy could not stay unchanged in the course of history. One of the main reasons lies in the fact, that some folklore types, having the direct relation to our epic heritage, began to disappear, assimilating in the other folklore types, and some of them began to change their functions. For instance, if at one time uzans disappeared at all from the historical arena, then, baksy paid their entire attention to cult songs. Zhyray (in the meaning zhyrshy - A.B.) began to bear the name of the epic narrators. Not only to name, but together with their closest relatives zhyrshy, they totally devoted themselves to the epic narration. In the other cases - in numerous regions, although the narrators were named zhyrshy, the word "zhyrau" was sometimes used in relation to tolgau narrators, and sometimes to the narrators of epic songs, thus preserving its initial meaning. The zhyrshy-improvisers, being supplemented by the zhyrau (narrator) group, not only narrate the learnt ready-made texts, but they turned out to be connected with epos formation and development. Afterwards, these two names of folklore types became the reason of disagreement in science about oral-poetic art. If some scientists suggest naming zhyrau only the creators (authors) of tolgau, then the others speak, that the narrators were zhyrau that is why they shall be named in this way. Some folklorists, understanding this process incorrectly, expressed logically incorrect ideas.

\subsection{Concerning the notion "zhyrshy"}

The term "zhyrshy" and their role in the following period were described in detailed and solid papers, which tried to define the functions of zhyrshy. Thus, R. Berdibaev notes, that zhyrshy, as understood by the wide circle of people, learned the famous texts and narrated them unchanged. However, the appearance of zhyrshy, as other representatives of art of oratory, is many-sided. Zhyrshy not only learn the ancient dastans and epic pieces, but develop them in definite direction. Evaluating the work of zhyrshy, who continue and develop epic traditions, it is necessary to remember:

1) they do not subject the song variants to great changes, narrate them, preserving their poetic form;

2) the questions of difference of zhyrshy repertoire; they can be considered as the peculiarities among different narrating schools;

3) the presence of different level of acting skills of zhyrshy. It is connected with the narrator's talent, his experience and education;

4) the narration of epos and dastans with great changes of initial text.

The term "zhyrshy" is also met in such Turkic-language nations, as the Kirghiz, the Uzbek, the Karachay and the Yakut. M. Bogdanov tells about the specific peculiarities of Kirghiz narrators: "The zhyrshy of the Kirghiz is divided into two groups: irchi - the performers of small songs, who sometimes sing the fragments from poems, and zhomokchu - the performers of large poems "Manas". R. Ortabaylany writes about the Karachay narrators, that the folk zhyrchy were the 
singers, guardians of folk songs and their popularizers. V.M. Zhirmunsky and Kh.T. Zarifov underline, that the performers of epic pieces in Bulungursk region are called dzhirchy.

Yakut investigators named the first narrators of olonkho as sesen (sheshen) "speaker", and then - yrya (zhyrshy). A.Z. Kholaev provides interesting facts about Karachay narrators. He writes that in some cases they turn to prose, and in other cases - to poems, sometimes combining them. When the epic text is being sang, several people from the listeners sing along with the singer (zhyrshy).

A typical feature of the Kazakh folklore is in the fact, that one art representative rarely combines organically different features: he is the creator and the narrator of pieces. Besides, if to consider, that the Kazakh narrators memorized eloquent, scintillating with wit, tolgau, terme and epic pieces, moreover, not only theirs, but also the ones of the contemporaries, we can confidently state, that both zhyrshy and zhyrau are the representatives of syncretic art, i.e. they are the narrators, musicians, artists, speakers and poets of their time.

Zhyrau, zhyrshy, kissashy, terme-shy, the same as Kirghiz manaschy and zhomokchy, Kara-Kalpak zhyrau and baksy, Uzbek bakhshy, shoir, dzhirchy, Turkmen bakhshy, Yakut olonkhosuty, Russian narrators, Azerbaidjanian ashugy, Kalmyk dzhangarchy, Buryat ulegershy, Karachay zhyrchy, Oirot tulchy were preserved as epic narrators from all folklore types of Kazakh nation.

\section{Discussion}

\subsection{Traditions in the art of narration}

In thorough analysis of art of the Kazakh narrators, it is possible to observe general and specific traditions. Thus, it is possible to mention as an example the legends and stories, comments and clarifications, how the future narrators acquire this type of oral culture. This process is equal, and it is described in general folkloristics. Thus, the Anglo-Saxon legends and stories narrate, how the talented Kedmon (shepherd) slept in the heath. He saw a stranger in his dreams, who bestowed him with the narrating word, thus, he became a narrator. The statement of Oyrot tulchy Eten-Gonchik about the acquisition of this art is also of great interest: "The giant approached the dazed Eten-Gonchik and asked, if he wanted to learn to sing the bogatyr songs... The giant stroke Gonchik's shoulder and disappeared... From this moment Eten-Gonchik felt the ability to sing the heroic ballads, became a famous rhapsode and admitted, that the got the gift from the tzar of dragons, coming under the image of the giant".

Such legends and stories were widely spread in the nations of the Middle Asia. Thus, for instance, the Kirghiz manaschy Tynybek told, that once he fell asleep in the heath and saw Manas and forty chora (horsemen) in his dream, they advised him to narrate "Manas". Many Uzbek bakhshy say, that they become bakhshy at the pleasure of Allah. The Turkmen bakhshy Nadzhef-oglan told, that he saw forty horsemen in his dream and poured the song in the view of wine into his mouth. There are such legends and stories about the majority of the Kazakh narrators. Let us pay attention to the statement of Abyl-zhyrau (the tutor of Muryn): he was one of the first, who narrated the cycle "Kyrymnyn kyryk batyry". He told, that when he was at thirty, at early morning he let the sheep go to grass and fell asleep. Somebody poured him some liquid, he swallowed. When he woke up, he felt the spring of song, the well of poetry, boiling in his heart: from that moment he became the akyn.

Such legend, connected with Bazar-zhyrau, is narrated in the following form: "As a child, when I pastured lambs, I fell asleep. I saw a man in white clothes, with white beard and white stick in my dream, he asked: "My dear child, shall I give you on your forehead or on your tongue". I replied: "The old man, give me on my tongue". I woke up because I was singing" (Aldashev, 1986). The same legend was told about Kozhabay-zhyrau, but in his dream, he was asked: "What would you take - the song or the dish?" (the leather dish for milking). Kashagan-zhyrau in the legend was asked: "How will you take - with case (full of treasure) or the bag?"

There is one more problem, deserving the attention. The stories and legends of Turkic-language nations not only narrate about the secrets of acquisition of the narration art, but also underline, that it is a special sign of public trust. Thus, the epos of Kirghiz nation "Mana" is narrated, connecting it with the choras of Manas, the number forty, white appearance. The stories, involved in it, constitute from the songlike rhymes (mandayna - tandayna, kogen-olen, arbalapdorbalap). One of these rhyme pairs means the material wealth, another one - any notion of art. As it is said, not for the sake of a witty remark, but for harmony. These notions have the deep implications.

There are the legends in Kazakh folkloristics, not only about one or another representative of the art of narration, but about ordinary people, not possessing any creative giftedness. They are the legends, that each man has his own totem (for instance, tiger, ox, fox) or any bird. Thus, there is the story that Zhambyla had a totem in the view of lion, and Kempirbay had a pigeon. Shashubay Koshkarbaev once told the following: "At fourteen, I saw a dream, that I am a bird, 
flying from hill to hill, picking different fruits, as if a bird. After this dream I began to sing songs".

Of course, it is impossible to pay no regard to the fact, that the talented people, showing interest to the art, see dreams. To understand this secret, it is necessary to investigate thoroughly their life and peculiarities of the development of their creativity. Later, people, devoted their life to the art, told, how they acquired the narration. They all, without exception, knew from childhood the power and strength of word, totally psychologically devoting themselves to its acquisition. They listened to the pieces of advice and instructions of famous art representatives, considered them to be the inspirational people. Obviously, it is the reason why they had one purpose and one goal to acquire the art of oratory, that is why they saw the songs and the whole epic pieces in their dreams. The words "a gift of the gab", "acquired the word" are used to express this notion only in folk environment. Indisputably, they tried to sublime themselves in the eyes of others. However, for instance, manaschy, clarifying, how they acquired the art of narration ("the song sat"), do not like to tell about their tutors, and the Kazakh and Kara-Kalpak narrators always tell about them with respect, naming five-six people, who taught their tutor.

\subsection{The role of musical instruments in the art of narration}

One of the main traits of narration tradition is the wide use of musical instruments. The shepherd's pipe, the pipe is one of the first musical instruments, named in connection with the narration of pieces of the Kazakh epos. Karachay use the name "sybyzgy" for this musical instrument, meant for playing a typical motive for lyrical-epic pieces (kyui), and the Balkar name it "sybyzkhe". Kobyz is named as the first musical instrument, which was directly used by the Kazakh narrators. Although A. Konyratbaev considers kobyz as the musical instrument, used by the narrators of Orkhon-Yenisei songs. It was firstly used by the baksy, directly connected with the art of oratory. This musical instrument, which was used for a long time for singing, after such akyns, as Marabay, Nysanbay and Zhanak, became the cult instrument of Baksy; it was also used to play the melodies of kyui. Since old times, the Uzbek narrators also used kobyz (kubuz), as well as the Karachay-Balkar (kygyl kyobuz), the Oyrat (khur), the Tatar, the Kabardian, the Ossetian (kapyr kobyz).

As it is said, the musical instrument "dombra" traces its genealogy from kobyz, and it is widely used by the Kazakh narrators. Singing, playing the kyui melodies, and the art of narration in whole, does not go without dombra. As is known, in due time, there were three-stringed types of dombra. It is convenient in transport, it can be used to play splendid musical motives; this instrument is one of the important components, necessary to acquire the art of narration.

One more peculiarity of the art of narration shall be noted. It is known, that the narrators, prior to singing, play kyui thoughtfully for a long time. This moment is explained by O. Nurmagambetova: "...zhyrau does not start epos at one time. At the beginning, he prepares himself and the audience...". Thus, prior to narration, Zhambyl and Nurpeis played kyui (musical plays and plots) (Nurmagambetova, 1988).

B.G. Erzakovich, studying the peculiarities of narrative motives, writes that Shakir Abenov, prior to narration of "Kyz-Zhibek", played the kyui "Koramzhay" for a long time (Erzakovich, 2006). The roots of this unique phenomenon, obviously, go far deep to the past. This is evidenced by the fact, that the Kazakh folklore has a lot of kyui, the names of which are assonant to the epic pieces, "Kambar", "Korogly" and others. It is one more problem, requiring special investigation of musical experts. The majority of improvisers traditionally used narration and presentation of zhel in their practice. Their repertoire has the wide-scale epic pieces, as well as tolgau and terme. They participate in aytys, trying to take into consideration the will and wishes of their admirers. By tradition, the narrators, who resort to rhymed prose, ask in the song, what the audience would like to listen to, and then, according to their creative capacities, create one plot line, zhel, i.e. the integral system, uniting several short plots. One more reason for this large plot line is the pleading, the entreaty of narrators for the inspiration to come to them, their psychological preparation prior to large pieces narration. 0 . Nurmagambetova clarifies this phenomenon in the following way: "The necklace of song" is narrated, firstly, in order to prove, that the narrators know many different dastans. Secondly, for the listeners to choose themselves, what they want to listen to, and also to understand, what epic piece will be met with the greatest interest" (Nurmagambetova, 1988).

Although not as zhel, but to cause inspiration and to prepare the organism for epos narration (body warming-up), the Uzbek and Kara-Kalpak nations preserved the propaganda of terme; it reveals deep roots of this tradition. The Kazakh had zhel performance till the lattermost times. Although the materials and zhels of Marabay, Mergenbay and other narrators survived, unfortunately, their narration was not recorded. That is why, A. Tazhibaev tells the following about the zhel narration by Nurpeis, who, at that times, yield to non in mastery: "Visiting us, Nurpeis narrated the zhels at the beginning; told the plot of each large dastan briefly and laconically. The scientist mentions the following about Zhambyl: "He tipped off that he would tell about former ancient times, about the batyrs Suranshy, Utegen, about the circumstances of time. He told about the connection with the Kirghiz, about "Manas", and then he asked the listeners: "What would you like to listen, maybe, Korogly?" He told, that he could sing about Suranshy and Sauryke for two days" 
(Tazhibaev, 1981). Such evidences of listeners are quite valuable.

\section{Conclusion}

The following conclusions were obtained in the process of analysis of the Kazakh narrative art - the original and unique phenomenon in the history of our culture:

The Kazakh epos was being developed and is being developed in conditions of vivid oral tradition. The public presented not only the listener, but also that distinguished epic environment, where the epic songs were formed, preserved and narrated.

Its narrators are the talented representatives of nation; the narrators fulfilled the cultural-enlightened and educational functions. The rich folklore heritage of the Kazakh nation presents the following folklore types of epos creators and bearers. They are uzan, baksy, zhyrau, zhyrshy, kissashy, termeshy.

At definite historical cut, some of them disappeared at all (uzan), the others changes their functions (for instance, baksy, zhyrau), and the third, soaking up the creative qualities of their predecessors, became the many-sided folklore types (zhyrshy).

This problematics is quite relevant, as the problem about the evolution of ancient types of the Kazakh folklore bearers is still understudied. Thorough characteristics of each type are required from the historical-cultural point of view.

\section{References}

Aiymbetov, K. (1988). Folk wisdom (pp. 434). Nokus.

Aldashev, Sh. (1986). Bazar-zhyrau (pp. 8). Alma-Ata: Zhazushy.

Bartold, V.V. (1986). The first volume. Composition (pp. 95). Moscow: Literature.

Berdibaev, R. (1999). Inexhaustible richness (pp. 388) Almaty: Mektep.

Borovkov, A.K. (1998). The problems of study of Turkic-language epos. The Problems of Epos Study, 11, 69.

Valiakhanov, Ch.Ch. (1984). The first volume. Collected works (pp. 578). Alma-Ata: Kazakh Soviet Encyclopedia.

Veselovsky, A.N. (2009). The historical poetics (pp. 324). Leningrad: High School.

Erzakovich, B.G. (1987). Hundred of Kazakh songs (pp. 387). Alma-Ata: Science.

Zholdasbekov, M. (2000). Valuable directions (pp. 436). Almaty: Zhazushy.

Zhubanov, E. (1987). The epic language (pp. 184). Alma-Ata: Science.

Korkyt Ata Book (pp. 105). Alma-Ata: Science.

Konyratbaev, A. (1987). The Kazakh epos and Turkic language studies (pp. 571). Alma-Ata: Science.

Magauin, M. (1971). The witness of ancient world. Aldaspan, 8, 43.

Margulan, A. (1985). The ancient zhyr, legends (pp. 368). Alma-Ata: Science.

Nurmagambetova, O. (1988). The Kazakh heroic epos "Kobylandy Batyr" (pp. 431). Alma-Ata: Science.

Sagitov, I. (1962). Kara-Kalpak heroic epos (pp. 411). Tashkent: FanUzSSr.

Smirnova, N.S. (1979). The Kazakh singers of the XVII century: akyns and zhyrau. Brief Report of the Institute of Oriental Studies of the Academy of sciences of the USSR, 1, 22.

Tazhibaev, A. (1981). The fifth volume. Collected works (pp. 587). Alma-Ata: Mektep.

Tursynov, E. (2003). The ancient representatives of the Kazakh oral literature (pp. 423). Almaty: Gylym.

Formozov, A. (1969). The essays on the primitive art (pp. 7). Moscow: Fiction. 